\title{
SISTEMAS DE GERENCIAMENTO AMBIENTAL, TECNOLOGIA LIMPA E CONSUMIDOR VERDE: a delicada relação empresa-meio ambiente no ecocapitalismo
}

Philippe Pomier Layrargues

Biólogo, Especialista em Educação e Planejamento Ambiental pela UFF, Mestre em Psicossociologia de Comunidades e Ecologia Social pela UFRJ e Doutorando em Ciências Sociais na Unicamp. E-mail: layrargues@ax.apc.org

\section{RESUMO}

O texto sustenta o argumento de que a ISO 14000 não resolverá a complexa problemática ambiental brasileira. Postulamos aqui que a sua incorporação na empresa não representa ainda uma mudança paradigmática em direção à sustentabilidade, mas sim uma mudança da cultura empresarial provocada mais pelas transformações político-econômicas mundiais do que por uma possível conscientização ambiental. Apesar de a tecnologia limpa ser apontada como a maior vantagem competitiva contemporânea no atual cenário de desregulamentação governamental, seu alcance ainda é limitado devido à sua intrínseca dependência da demanda de um significativo mercado verde.

\begin{abstract}
The text supports the argument that ISO 14000 will not solve the complex problems of Brazilian environment. It is postulated that its incorporation in business does not yet represent a paradigmatic change in the direction of sustainability, rather representing a change in the business culture caused more by the changes in the world political economy than by a possible environmental consciousness. In spite of the clean technology appearing to be the greatest contemporary competitive advantage in the actual scenario of governmental deregulation, its reach is still limited to its intrinsic dependence on the demand of a significant green market.
\end{abstract}

\section{PALAVRAS-CHAVE}

Ambientalismo, ideologia, mercado, consumidor verde, tecnologia limpa.

KEY WORDS

Environmentalism, ideology, market, green consumer, clean technology. 
O AMBIENTALISMO E O

QUESTIONAMENTO DA SOCIEDADE INDUSTRIAL DE CONSUMO

O ambientalismo, movimento histórico originado a partir do recente reconhecimento dos assustadores efeitos negativos da intervenção antrópica na biosfera, em sua crítica ao modelo civilizatório ocidental, reprovou os paradigmas norteadores da sociedade industrializada de consumo. Como alternativa, propôs que se efetuasse uma alteração no rumo das coisas, objetivando a elaboração dos pilares de uma nova era, pautada a partir de agora não mais no esgotamento da natureza mas na sustentabilidade ambiental.

Sobre a alteração do rumo das coisas, cuja questão relevante diz respeito à necessidade de desvio da rota de colisão em que a civilização industrial se encontra, Soffiati (1987) fez uma alusão à imagem metafórica do veículo dirigindo-se em alta velocidade em direção ao precipício. Diante desse panorama, duas alternativas despontam como possibilidades de enfrentamento do risco da catástrofe: pisar no freio e diminuir a velocidade para mudar de rumo ou pisar no acelerador para ganhar impulso e saltar o precipício. A mensagem da metáfora é clara: mais vale a pena garantir a continuidade da vida e mudar de rumo do que arriscar-se numa tarefa suicida.

Isso quer dizer que o modelo de desenvolvimento convencional - pautado no mercado como instância reguladora da vida social, em que a política de desenvolvimento científico-tecnológico ocorre sobretudo em função da demanda do mercado em maximizar o lucro - conduz-nos velozmente em direção ao precipício, ao mesmo tempo em que advoga que este mesmo padrão tecnológico convencional que nos colocou nessa situação será capaz de encontrar as soluções. Postula que sairemos da crise acentuando aquilo que nos trouxe a ela, apesar de o bom senso dizer que é mais prudente alterar todo o estado das coisas presentes na doutrina da economia neoclássica.

O físico Fritjof Capra (1982) foi quem melhor traduziu o significado dessa proposta de transformação, ao postular a proximidade de a humanidade atingir um ponto de mutação, no qual as forças competitivas cederiam lugar às forças cooperativas, o individualismo seria substituído pelo coletivismo, a visão de mundo reducionista cederia vez à sistêmica e o curto prazo seria suplantado pelo longo prazo. Desencadeada por uma marcante presença de valores pós-materialistas, numa clara ruptura com a ordem instituída, a idéia básica que norteia o pensamento ambientalista original, intitulado de ambientalismo radical, incide na proposição da alteração de paradigmas, deslocando o eixo da racionalidade econômica para a

\section{A IDÉIA BÁSICA QUE NORTEIA O PENSAMENTO AMBIENTALISTA ORIGINAL INCIDE NA PROPOSIÇÃO DA ALTERAÇÃO DE PARADIGMAS, DESLOCANDO O EIXO DA RACIONALIDADE ECONÔMICA PARA A ECOLÓGICA.}

ecológica, na qual o mercado deixaria de ser considerado como a única e majoritária instância reguladora da sociedade e determinante da economia, cedendo espaço crescentemente à natureza, com seus princípios ecológicos para cumprir essa função em igualdade de condições. Em outras palavras: as leis da natureza encontrariam espaço na imposição de normas sociais na mesma medida em que as leis do mercado impõem as suas regras. Com a superação do antagonismo verificado na relação entre desenvolvimento e proteção ambiental, teríamos assim a substituição do confronto pela compatibilização dos interesses entre economia e ecologia.

\section{SURGE O AMBIENTALISMO EMPRESARIAL}

E, então, o século XX, marcado na história da humanidade pela iminência de abrigar a maior catástrofe ecológica de origem antropogênica, parece ter chegado, no limiar do século XXI, a uma grande solução de seus problemas. O ambientalismo empresarial, sobressaindo-se desde o início da década de 90 na comunidade ambientalista como o promotor do desenvolvimento sustentável, apresenta o que finalmente parece ser a solução do impasse ecológico: a ISO 14000, o grande avanço em direção à produção industrial limpa e, conseqüentemente, ao 
equacionamento da problemática industrial relativa ao ambiente.

Parece que a indústria entrou mesmo nos eixos. Dos anos 70 até meados da década de 90 , podemos demarcar uma fronteira muito clara da atuação empresarial relativa ao meio ambiente. Da típica postura reativa própria dos anos 70 , em que se considerava a relação entre proteção ambiental e desenvolvimento como absolutamente antagônica, uma parte do setor empresarial assumiu uma postura proativa e inseriu-se na comunidade ambientalista em meados da década de 80 como um dos seus membros mais expressivos, ganhando destaque no início da década de 90. Defensor incansável do modelo de desenvolvimento sustentável, advoga a total complementaridade entre a proteção ambiental e o desenvolvimento (Viola, 1992).

Acusado pelo ambientalismo radical num recente passado de ser irresponsável para com o meio ambiente por não adotar qualquer mecanismo de prevenção da poluição e dos possíveis acidentes ambientais, conhecido por todos como o vilão da ecologia, pois só assumia os constrangimentos ambientais compulsoriamente por imposição da legislação ambiental, hoje o setor empresarial possui membros considerados como os amigos do verde, dotados de elevado grau de responsabilidade ambiental, cuja adesão ao pacto ecológico ocorre de uma forma sobretudo voluntária, apontada por muitos como fruto do aumento da consciência ambiental (Souza, 1993; Tankersley, 1994; Fortes, 1992; Donaire, 1994; Maimon, 1992).

Coerentemente apresentado, o discurso empresarial verde anuncia uma mudança do rumo proposto em relação ao estilo de desenvolvimento convencional, contornando a omissão das empresas num recente passado extremamente poluidor. Sensibilizadas com a questão ambiental e sinalizando o início de um processo de transição ideológica, teriam agregado os princípios ecológicos ao modus operandi da produção industrial, marcando o início de uma nova fase, baseada nos critérios da sustentabilidade ambiental. O Sistema de Gerenciamento Ambiental (SGA) implantado nas empresas torna-se, a partir de agora, o elemento-chave responsável pela adequação dos interesses empresariais privados à manutenção da qualidade ambiental coletiva e permitirá um significativo avanço na relação entre empresa e meio ambiente. O SGA representa a estratégia empresarial para a identificação, por meio de planos e programas de caráter preventivo, das possíveis melhorias a serem realizadas com o intuito de conciliar definitivamente a lucratividade em- presarial com a proteção ambiental, versando tanto nos produtos como nos processos industriais.

De mãos dadas com a criação do mercado verde, o estabelecimento de normas ambientais internacionais visa a homogeneizar conceitos, padrões e procedimentos industriais relativos à questão ambiental, tendo em vista que, atualmente, o cenário comercial, além de globalizado e altamente competitivo, abriga empresas que abusam na autoconcessão de selos verdes, que nada mais são do que rótulos nas embalagens atestando qualidades ambientais muitas vezes questionáveis, iludindo o consumidor por meio de estratégias escusas de marketing ecológico (Reis, 1995; Hurtado, 1996/7; Weiss, 1997). Nesse contexto, a abertura dos mercados pela globalização da economia acaba por exigir a criação da ISO 14000, mecanismo capaz de atuar como um fator regulador da competição, normatizador das práticas de marketing e limitador das barreiras comerciais no mercado.

\section{A TECNOLOGIA LIMPA COMO A SOLUÇÃO AMBIENTAL}

A tônica do discurso empresarial verde sustenta que a incorporação da ISO 14000 nas indústrias freqüentemente exige a concomitante instalação de tecnologias limpas, e, como estas se configuram no instrumento privilegiado de competitividade empresarial, ocorrerá naturalmente - independentemente da coerção governamental por meio de instrumentos de controle da poluição tradicionais - uma paulatina adesão empresarial para efeitos de incremento de competitividade, até que todas as empresas completem a transição em direção à sustentabilidade.

Há um elevado nível de otimismo perante as expectativas do SGA, considerando que, apesar do caráter voluntário, virtualmente, todas as corporações empresariais de qualquer porte serão envolvidas nesse processo, simplesmente por se considerar a tecnologia limpa como a vantagem competitiva no cenário comercial contemporâneo.

Vários autores (Reis, 1995; Maimon, 1996; Badue, Maimon e Singer, 1996; Mi- 
neiro, 1996; Nahuz, 1995; D’Avignon, 1994) afirmam que o componente ambiental chegou para ficar e que a empresa moderna, indistintamente de seu porte, estrutura ou setor, tem de adaptar-se aplicando os princípios de gerenciamento ambiental para não perder espaço na competitividade empresarial. Caso contrário, a saída do mercado ou a própria falência parece ser o destino mais provável para quem ficar de fora do processo. Uma nota divulgada no periódico Senac e Educação Ambiental (Senac, 1996, p. 33) afirma que: "de acordo com o Comitê Técnico 207, a certificação ambiental terá um caráter voluntário, mas, sem dúvida alguma, todas as empresas deverão procurar responder às exigências do sistema de qualidade ambiental, já que elas serão determinantes na competitividade dos produtos e serviços nacionais no mercado mundial." Como conseqüência da sedutora potencialidade de a ISO 14000 transformar-se no elemento da vantagem competitiva atual, vários manuais têm sido produzidos com o intuito de divulgar amplamente os princípios do gerenciamento ambiental (Maimon, 1996; Reis, 1995; Cajazeira, 1997; Do Valle, 1997; Jöhr, 1994; Lambert, 1994; Binet e Livio, 1993; Elkington, 1991).

Nessa perspectiva, a poluição industrial, com todas as suas mazelas, teria, a partir de agora, seus dias contados. Simpatizantes da causa ecológica, ambientalistas em geral e consumidores verdes em particular, todos saúdam essa iniciativa e, aliviados, respiram esperançosos com a proximidade da resolução da crise ambiental no âmbito industrial.

\section{MUDANÇAS QUE CONFUNDEM: POR UMA NOVA INTERPRETAÇÃO DE COMO E POR QUE SURGIU O AMBIENTALISMO EMPRESARIAL}

Diz um ditado popular que as aparências enganam, pois o hábito não faz o monge. Portanto, deixando de lado as aparências e mergulhando na essência da questão, vislumbramos a face oculta da ISO 14000 , em sua apologia retórica, que advoga o nascimento de uma nova era. É necessário, então, esclarecer algumas questões mal colocadas quando se afirma que estamos presenciando um período de mudança paradigmática.
O que é apresentado pelo discurso empresarial verde como uma mudança representa apenas uma singela reforma, uma adequação às novas realidades em conformidade à nova ordem mundial, o que de modo algum pode configurar-se numa transformação paradigmática. É verdade que ocorreu um grande avanço em relação à cultura empresarial típica da década de 70; todavia, esse argumento não se encerra em si só e muito menos pode ser apresentado como uma meta cumprida, cujo objetivo

\section{COM A ISO 14000, O CONTROLE AMBIENTAL PASSA PARA O ÂMBITO DA SOCIEDADE, QUE TERIA NO CONSUMIDOR VERDE O EFEITO REGULADOR DA MÃO INVISÍVEL, FUNCIONANDO POR MEIO DA LEI DA OFERTA E PROCURA.}

tenha sido plenamente atingido. A incorporação do constrangimento ambiental na indústria por meio da ISO 14000 representa uma etapa de um longo processo que caminha em direção a uma era de sustentabilidade.

As palavras que vêm sendo utilizadas para verbalizar a dinâmica das transformações que ocorrem na questão ambiental são carregadas de cargas ideológicas indissociadas das estruturas ideológicas de quem as formula. Por exemplo, o próprio título do livro considerado a bíblia do ambientalismo empresarial, Mudando o rumo (Schmidheiny, 1992), sugere que, na metáfora utilizada por Soffiati, o veículo que segue em direção ao precipício teria alterado a sua rota de colisão. É a partir dessa simples enunciação que ocorre a manipulação discursiva cujo intuito reside na vinculação da reestruturação empresarial em função da nova realidade econômica - fenômeno extremamente bem esclarecido por Peter Drucker (1993) - aos princípios enunciados pelo ambientalismo radical.

Uma análise de conjuntura sistêmica, enfocando tanto a relação usualmente considerada a respeito da interação entre a empresa e o meio ambiente como também os aspectos econômicos, políticos e tecnológicos, é suficiente para a constatação de que a incorporação da variável ambiental nas empresas par- 
tiu sobretudo de uma sensibilização econômica, e não ecológica, como vem sendo comumente apontado. Essa percepção já sinaliza que tal óptica não corresponde propriamente a um processo de transformação paradigmática, ou seja, uma transição ideológica da racionalidade econômica para a ecológica (Layrargues, 1996).

O pano de fundo dessa questão advoga que o setor empresarial vem promovendo uma mudança desde o início da década de 90, quando assumiu uma atitude positiva para com o meio ambiente, mas não mais compulsoriamente, por causa da rigidez da legislação ambiental, e sim voluntariamente, por vislumbrar oportunidades de negócio, ao agregar a variável ambiental na dimensão empresarial. Da postura reativa, passou para a atitude proativa. E, assim, antecipar-se à legislação ambiental não significaria mais apenas manter ações preventivas para evitar acidentes e riscos ambientais, mas sobretudo obter uma vantagem competitiva no mercado, localizada na variável ecológica. Percebeu-se que o que era considerado um dejeto poderia muitas vezes tornar-se um recurso e, nesse sentido, o primeiro passo em direção à sustentabilidade correspondeu à economia de recursos naturais e energéticos, diminuindo, como conseqüência, o desperdício e a poluição.

Em paralelo, no bojo das alterações, o setor empresarial - representado sobretudo pelas transnacionais - procura promover mudanças no arranjo institucional interno, em que o modelo toyotista substitui o modelo fordista, visando a conferir uma crescente flexibilização no processo produtivo e uma descentralização no processo decisório, medidas necessárias diante do crescimento do mercado asiático.

Além disso, as recentes inovações tecnológicas foram dirigidas para produção das tecnologias limpas ${ }^{1}$ como uma resposta aos condicionantes da legislação ambiental, das seguradoras, dos acionistas, das barreiras comerciais e da suposta pressão do consumidor, exigindo uma atuação empresarial mais responsável com o meio ambiente, ao contrário do postulado referente à adesão empresarial voluntária ao pacto ecológico. Somente a partir da criação das tecnologias limpas, viabilizou-se a mudança de atitude empresarial.

No entanto, atestar o crédito da promoção da mudança da cultura empresarial apenas ao meio ambiente revela o uso de uma fachada que encobre a verdadeira face do processo: a globalização da economia no contexto político neoliberal. O peso da variável ambiental na mudança empresa- rial de fato é significativo, mas nunca foi determinante. O que está por trás da nova ordem mundial não é tanto o imperativo ecológico, mas sim a conjuntura neoliberal, aplicando seu rearranjo no eixo políticoeconômico internacional, em que se deslocou a vantagem competitiva da matriz tecnológica de mão-de-obra intensiva para capital intensiva, originando, assim, as novas tecnologias, que, num movimento de interesses convergentes entre o acréscimo de produtividade industrial e a demanda ecológica, produziram a tecnologia limpa. A transição industrial orientada pela modernização tecnológica visa, em primeiro lugar, a reduzir custos para aumentar a competitividade. Se esse feito for benéfico ao meio ambiente, tanto melhor, pois controlar a poluição também representa uma economia de recursos, além do que a aquisição de uma imagem empresarial positiva diante da opinião pública também se constitui num valioso recurso altamente explorável nas campanhas de marketing.

Em síntese, o interesse pela manutenção da qualidade ambiental no âmbito empresarial só fez sentido, e tornou-se viável, quando a globalização da economia colocou o mercado mundial sem fronteiras nacionais estabelecidas, rompendo com as clássicas fórmulas de protecionismo comercial, o que provocou um forte acirramento da competição empresarial, redundando na alteração do tradicional conceito da vantagem competitiva, que se deslocou da mãode-obra intensiva para capital intensiva, expressa pelo domínio das inovações tecnológicas. Aqui, diante da nova subjetividade visando à incorporação de critérios ecológicos, o desenvolvimento tecnológico caminhou em sintonia com a necessidade de imprimir maior eficiência econômica ao acréscimo de produtividade com as tecnologias limpas, poupadoras de recursos naturais, energéticos e de mão-de-obra.

É preciso ter consciência de que a questão ambiental, em grande medida, está sendo utilizada para camuflar as transformações ocorridas no seio do capitalismo, em sua invisível transição da fase liberal para a neoliberal, na qual agora se advoga a retirada total do Estado na regulação da economia nas sociedades industrializadas de con- 
sumo, numa conjuntura cujo cenário comercial está absolutamente globalizado e ferozmente competitivo. O Estado empresário tornou-se desnecessário diante da velocidade imprimida pelas transformações globais, e sua tarefa de estímulo à competitividade empresarial já estaria concluída. Nesse contexto, toda uma estratégia foi articulada para retirar do Estado qualquer resquício de atuação comprometedora da livre atuação empresarial. Em nome da livre iniciativa, o fluxo financeiro dos mecanismos de controle da poluição, por exemplo, desloca-se do eixo empresa-governo, via aplicação de multas, e tende a girar em torno do setor empresarial, por meio das bolsas de resíduos e poluição. Assim, o Estado perde o pouco que lhe resta do controle econômico.

A tônica do discurso do ambientalismo empresarial, baseada na apropriação da proposta ecologista da "mudança de rumo para uma nova era", visa a fazer com que a sociedade imagine que o setor empresarial está materializando o sonho ecologista: uma revolução paradigmática, por meio da mudança dos valores que sustentam a ideologia da sociedade de consumo. Dessa forma, em vez de a racionalidade econômica dirigir as relações sociais e econômicas, quem cumpriria essa função seria a racionalidade ecológica.

\section{O CONSUMIDOR VERDE COMO UM ELEMENTO ESTRUTURADOR DA VARIÁVEL AMBIENTAL NA EMPRESA}

Desponta, nesse contexto, o consumidor verde, que é aquele em cujo poder de escolha do produto incide, além da questão qualidade/preço, uma terceira variável: o meio ambiente, ou seja, a determinação da escolha de um produto agora vai além da relação qualidade e preço, pois este precisa ser ambientalmente correto, isto é, não prejudicial ao ambiente em nenhuma etapa do seu ciclo de vida. Dizem até que, de agora em diante, o simples ato da compra determina uma atitude de predação ou preservação do ambiente, transferindo o ônus da responsabilidade ambiental à sociedade, não mais ao mercado ou Estado.

Tudo gira em torno da regulação da economia em função da competitividade no mercado globalizado, que teria, no consumidor verde, mais do que um termômetro aferindo a exigência por uma produção limpa, a verdadeira mola propulsora das tecnologias limpas. Com a ISO 14000, o controle ambiental, antes sob a responsabilidade do Estado, passa para o âmbito da sociedade, que teria no consumidor verde o efeito regulador da mão invisível, funcionando por meio da lei da oferta e

\section{O CENÁRIO BRASILEIRO AINDA NÃO PERMITE QUE O PLANEJAMENTO DAS POLÍTICAS AMBIENTAIS ENFATIZE $O$ ENFRENTAMENTO DA PROBLEMÁTICA AMBIENTAL NO ÂMBITO INDUSTRIAL UNICAMENTE POR MEIO DO MERCADO.}

procura. Essa é a justificativa de todo êxtase que precocemente comemora o seu sucesso, antes mesmo de sua aplicação cotidiana. É bem verdade que um completo aparato tecnológico de ponta se encontra à disposição do setor empresarial, todavia, ele só será utilizado caso venha a ser solicitado pelo consumidor verde, quando indicadores de vendas evidenciarem que as escolhas no mercado estão sendo selecionadas preferencialmente em função dos produtos ecologicamente corretos.

Com a perspectiva de um cenário sem regulação governamental, com frágeis mecanismos de aplicação das normas legais impositivas, o consumidor verde é o elemento considerado o mais importante no processo da ISO 14000, apesar de, curiosamente, ser também o mais frágil. O problema é que ele, sobretudo no Brasil, como na maioria dos países em desenvolvimento, ainda é totalmente inexpressivo no conjunto dos cidadãos consumidores, conforme se atesta pelos comentários de atores sociais envolvidos com a padronização das normas (Mineiro, 1996). O país ainda não possui uma presença significativa de consumidores verdes para que se configurem num verdadeiro estímulo à sujeição empresarial ao imperativo ecológico. A demanda por produtos verdes ainda é mínima. Dados de 1992, o período áureo de preocupação ambiental no país, indicam que apenas $18 \%$ dos brasileiros deixariam de 
comprar produtos considerados agressivos ao ambiente, contra uma porcentagem de 50\% de alemães dispostos a tomar a mesma atitude (Viladarga, 1992). Outra pesquisa de opinião (Doxsey, 1991), realizada em novembro de 1991 em Vitória, constatou que apenas $38,7 \%$ dos entrevistados mudaram de comportamento devido à preocupação com o meio ambiente e, desses, somente $8,1 \%$ deixariam de comprar produtos que de alguma forma pudes-

\section{VALER-SE DO CONSUMIDOR}

VERDE COMO O ELEMENTO

VIABILIZADOR DO PROJETO DESENVOLVIMENTISTA

NEOLIBERAL E ECOLÓGICO, SUSTENTADO PELA ALIANÇA

VISCERAL ENTRE A TECNOLOGIA

LIMPA E A RECICLAGEM, EQUIVALE

AINDA A IMPRIMIR A IDEOLOGIA

DO CONSUMISMO A TODO VAPOR.

sem agredir a natureza, revelando, assim, a precária estabilidade que representa o consumidor verde, elemento dependente de variáveis como o poder de compra, a satisfação das necessidades básicas e, sobretudo, a consciência ecológica.

Essa baixa porcentagem de consumidores verdes na sociedade brasileira reflete-se no próprio perfil empresarial que se manifesta sensibilizado com a questão ambiental a ponto de considerar como objetivo estratégico o desenvolvimento de tecnologias adequadas ao meio ambiente. Apesar da forte tendência de crescimento da demanda por tecnologias limpas no mercado, o número de empresas adequadas aos constrangimentos ambientais no Brasil ainda é relativamente baixo (Tigre, 1994).

Portanto, o consumidor verde seria hoje o alvo invertido da ISO 14000 se ele demandasse a certificação ambiental na empresa por meio do seu poder de escolha, boicotando produtos considerados agressivos ao ambiente. Esse é o desejo do ambientalismo empresarial, cioso do controle da regulação econômica em suas mãos, antecipando a retirada da responsabilidade do Estado quanto ao controle da poluição industrial. Para manter o Esta- do afastado, conforme rege o neoliberalismo, o setor empresarial terá que investir pesadamente em campanhas de educação ambiental que possibilitem aumentar o número de consumidores verdes na sociedade, imbuídos pelo mesmo ímpeto consumista de antes, árdua tarefa considerando-se que apenas $20 \%$ da população brasileira é de fato consumidora em sentido concreto.

É importante destacar que o SGA possui sua eficácia limitada à existência de um expressivo mercado verde, que demande uma produção limpa, o que, por enquanto, se limita ao caso do mercado europeu, e do norte-americano em menor expressão, e portanto, a vanguarda da gestão ambiental está nas empresas exportadoras e multinacionais, que lideram a mudança cultural (Badue, Maimon e Singer, 1996; Mineiro, 1996; Souza, 1993; Donaire, 1994; Fonseca, 1991; Torres, 1992). De fato, uma pesquisa (Gutberlet e Segura, 1996/7) constatou que apenas as empresas exportadoras encontraram motivos concretos para preocupar-se com a questão ambiental e, portanto, adequar-se aos princípios do gerenciamento ambiental, uma vez que o mercado interno ainda carece fortemente da pressão do consumidor verde.

Assim, nem todas as empresas são passíveis de reagir positivamente aos princípios do gerenciamento ambiental, pois o componente ambiental é um dado irrelevante para a realidade de muitas delas. Verificamos que um limitado número de empresas, embora dotadas de grande visibilidade, será estimulado a aderir ao SGA, mesmo que se considere o efeito cascata entre as empresas que operam no conceito da produção flexível, como as empresas da constelação das montadoras de automóveis.

Em suma, o cenário brasileiro ainda não permite que o planejamento das políticas ambientais enfatize o enfrentamento da problemática ambiental no âmbito industrial unicamente por meio do mercado. A pesquisa de Tigre (1994) demonstrou que a regulamentação governamental é o principal indutor da adoção de soluções ambientais pela indústria. O mercado, sozinho, é insuficiente para alterar o comportamento das empresas em relação ao meio ambiente. Assim, uma política pública de controle da poluição, por mínima que seja, é vital para 
a transição à sustentabilidade com uma gestão ambiental coerente, enquanto indicadores não apontarem a existência de um número significativo de consumidores verdes a ponto de tal fato implicar estímulos para a reconversão industrial às tecnologias limpas. Se se pensar conforme apontam Carneiro, Magyar e Granja (1993), que demarcam claramente os campos de atuação governamental e empresarial, verificamos em total transparência a disputa existente entre o domínio de atuação empresarial - a necessidade de produção, que gera impactos difusos sobre os recursos naturais - e o domínio de atuação governamental - a necessidade de planejamento e controle ambiental -, o que, portanto, determina a necessidade de uma estratégia de parceria, integração e co-responsabilidade entre os dois setores.

Nesse sentido, a tarefa fundamental a ser empreendida constitui-se na democratização tanto do Estado como da sociedade, cujo direito de informação sobre a qualidade ambiental associado à realização de amplas campanhas de educação ambiental constituem os elementos essenciais à transição para a sustentabilidade (Hazen, 1997).

Todavia, valer-se do consumidor verde como o elemento viabilizador do projeto desenvolvimentista neoliberal e ecológico, sustentado pela aliança visceral entre a tecnologia limpa e a reciclagem, equivale ainda a imprimir a ideologia do consumismo a todo vapor, colocando de lado a mola mestra do ambientalismo radical, que se referia à difusão de valores pós-materialistas como uma forma de minimizar o efeito deletério da cultura consumista.

\section{CONCLUSÃO: QUE MUDANÇA DE RUMO?}

Exposta essa argumentação, a proposta empresarial de "mudança de rumo em direção a uma nova era" perde seu fundamento. O núcleo central que representa a estrutura vital dos paradigmas norteadores da civilização industrializada de consumo permanece inalterado. Não ocorreram, nem estão em trânsito, mudanças no sentido de uma revolução paradigmática, pois a reforma que ora se presencia explicita apenas mudanças de comportamentos dirigidos ao estilo de consumo, e não mudanças de valores. Pode ser que a cultura do desperdício seja substituída pela cultura da reciclagem, mas essa é uma transição míope, pois, enquanto não se questiona a ideologia do consumismo, ela obedece unicamente ao interesse empresarial em recuperar sua matéria-prima ao menor custo possível.

\section{O DENOMINADOR COMUM} DO "ANTES" PARA O "DEPOIS" CONTINUA SENDO O INDIVIDUALISMO, O MERCADO, A COMPETIÇÃO, O CONSUMISMO, A PRODUTIVIDADE MÁXIMA, OU SEJA, AQUELES MESMOS VALORES QUESTIONADOS ORIGINALMENTE PELO AMBIENTALISMO RADICAL.

Além disso, é injustificável que, em nome da natureza, se utilizem tecnologias "limpas", mas que são responsáveis pela crescente onda de desemprego conjuntural que assola o planeta, já que postos de trabalho na indústria são substituídos pela robótica. A transição para a sustentabilidade não envolve apenas a questão ambiental, envolve também a social. Sociedades sustentáveis são criadas com base no enfrentamento conjunto das questões ambientais e sociais.

Não há uma mudança de rumo, pois a rota imprimida ainda não é compatível com a apontada pelo ambientalismo radical. A rota do ambientalismo empresarial apresenta-se como uma coalização entre o ecocapitalismo - que postula a necessidade da correção das imperfeições do mercado para enfrentar a questão ambiental (Leff, 1996) - e o ambientalismo moderado - que postula a possibilidade de corrigir alguns elementos do capitalismo, enfatizando a viabilidade de as inovações tecnológicas mitigarem a problemática ambiental -, o que representa, sob a óptica do ambientalismo radical, uma posição similar por adotar uma postura reformista.

Enfim, o denominador comum do "antes" para o "depois" continua sendo o individualismo, o mercado, a competição, o consumismo, a produtividade máxima, ou seja, aqueles mesmos valores questio- 
nados originalmente pelo ambientalismo radical em sua crítica ao modelo civilizatório ocidental. A certificação ambiental, interpretada pelo ambientalismo radical, simplesmente vem legitimar o mesmo modus operandi da produção industrial, apenas revestido de uma nova roupagem.

Afirmações puramente ideológicas procuram atualmente dar conta de toda a complexidade da questão ambiental. As soluções são apresentadas como respostas naturais e evidentes, mas sem qualquer embasamento teórico plausível de comprovação que demonstre um compromisso real com a mudança de rumo. Devemos, no mínimo, como sugere Przeworski (1993), agir com mais cautela diante de tal excessivo zelo ideológico que ensaia experimen- tos cujas implicações para o futuro da humanidade são por demais perigosas, pois o autor demonstra que os mercados livres e competitivos simplesmente não são necessariamente eficientes para promover o crescimento econômico e o bem-estar social.

O perigo da insinuação de vivermos sob o signo de uma nova era incide na promoção da ilusão de que não será mais necessário repensar o modelo civilizatório desejado para as gerações futuras, pois o neoliberalismo teria apresentado argumentos convincentes atestando sua vitória sobre qualquer outro modelo. Essa é a face oculta da ISO 14000 . O
REFERÊNCIAS BIBLIOGRÁFICAS

BADUE, A. F. B., MAIMON, D., SINGER, E. Gestão ambiental: compromisso da empresa. Gazeta Mercantil, São Paulo, mar./maio 1996.

BINET, L., LIVIO, C. Guide vert à l'usage des entreprises. Paris : Défis/AFNOR, 1993.

CAJAZEIRA, J. E. R. ISO 14001: manual de implantação. Rio de Janeiro : Qualitymark, 1997.

CAPRA, F. O ponto de mutação. São Paulo : Cultrix, 1982

CARNEIRO, J. M. B., MAGYAR, A. L., GRANJA, S. I. B. Meio ambiente, empresário e governo: conflitos ou parceria? RAE - Revista de Administração de Empresas, v. 33, n. 3, p. 68-75, 1993.

D'AVIGNON, A. et al. Gestão ambiental: um instrumento de competitividade, qualidade e adequação da empresa às normas e legislações ambientais. In: Anais do I Encontro Brasileiro de Ciências Ambientais, vol. I. Rio de Janeiro : UFRJ, 1994. p. 204-19.

DONAIRE, D. Considerações sobre a influência da variável ambiental na empresa. RAE - Revista de Administração de Empresas, v. 34, n. 2, p. 68-77, 1994.

Do VALLE, C. E. Como se preparar para as normas ISO 14000. Rio de Janeiro : Qualitymark, 1997.

DOXSEY, J. R. Pesquisa de opinião pública sobre meio ambiente e desenvolvimento no Estado do Espírito Santo. Vitória : NAPS/CONSEMA/UFES, 1991.

DRUCKER, P. F. As novas realidades. 3. ed. São Paulo : Pioneira, 1993.

ELKINGTON, J. et al. The green business guide. London : Gollancz, 1991.
FONSECA, P. S., NARDIM, M. Projetos de desenvolvimento e impacto ambiental: uma visão histórica sob a ótica do Banco de Desenvolvimento. Rev. Adm. Públ., v. 25, n. 4, p. 25-32, 1991.

FORTES, M. Desenvolvimento e meio ambiente: a visão empresarial. In: VELLOSO, J. P. (Org.). A ecologia e o novo padrão de desenvolvimento no Brasil. São Paulo : Nobel, 1992. p. 61-5.

GUTBERLET, J., SEGURA, D. S. B. Tendências de gerenciamento ambiental nas indústrias brasileiras. Debates Socioambientais, v. 2, n. 5, p. 26-8, 1996/7.

HAZEN, S. Democracia ambiental. Nuestro Planeta, v. 8 , n. 6 , p. 31,1997

HURTADO, M. E. Os consumidores e a ISO 14000. Debates Socioambientais, v. 2, n. 5, p. 8-10, 1996/7.

JÖHR, H. Overde é negócio. São Paulo : Saraiva, 1994.

LAMBERT, S. Manuel environnement à l'usage des industrie/s. Paris : AFNOR, 1994.

LAYRARGUES, P. P. A cortina de fumaça: 0 discurso empresarial verde e a ideologia da poluição. Dissertação (Mestrado) - Eicos/UFRJ, 1996.

LEFF, E. La capitalización de la naturaleza y las estrategias fatales de la sustentabilidad. Formación Ambiental, v. 7, n. 16, p. 17-20, 1996

MAIMON, D. Empresa e meio ambiente. Tempo e Presença, v. 14, n. 261, p. 49-51, 1992.

MAIMON, D. Passaporte verde: gestão ambiental e competitividade. Rio de Janeiro : Qualitymark, 1996.

MINEIRO, P. ISO 14000: nova era para a qualidade ambiental. Ecologia \& Desenvolvimento, v. 5, n. 61, p. 4-8, 1996.

NAHUZ, M. A. R. 0 sistema ISO 14000 e a certificação ambiental. RAE - Revista de Administração de Empresas, v. 35, n. 6, p. 55-66, 1995.
PRZEWORSKI, A. A falácia neoliberal. Lua Nova, v. 28/29, p. 209-25, 1993.

REIS, M. J. L. ISO 14000: gerenciamento ambiental: um novo desafio para a sua competitividade. Rio de Janeiro : Qualitymark, 1995.

SCHMIDHEINY, S. Mudando o rumo. Rio de Janeiro : FGV, 1992

SENAC. SENAC e Educação Ambiental, n. 5 , p. $30-3,1996$

SOFFIATI, A. As raízes da crise ecológica atual. Ciência e Cultura, v. 39, n. 10, p. 951-4, 1987.

SOUZA, M. T. S. de. Rumo à prática empresarial sustentável. RAE - Revista de Administração de Empresas, v. 33, n. 4, p. 40-52, 1993.

TANKERSLEY, A. M. Meio ambiente e ação empresarial numa visão integradora. Dissertação (Mestrado) - Eicos/UFRJ, 1994

TIGRE, P. B. (Coord.). Tecnologia e meio ambiente: oportunidades para a indústria. Rio de Janeiro : Ed. da UFRJ, 1994.

TORRES, H. A emergência das indústrias "sujas" no Brasil. Brasília, 1992. (Doc. de Trabalho do ISPN).

VILADARGA, V. Pesquisa mostra que os consumidores "verdes" no Brasil ainda são poucos. Gazeta Mercantil, 30 maio 1992.

VIOLA, E. 0 movimento ambientalista no Brasi (1971-1991): da denúncia e conscientização pública para a institucionalizacão e o desenvolvimento sustentável. In: GOLDENBERG, M. (Org.). Ecologia, Ciência e Política. Rio de Janeiro : Revan, 1992. p. 49-75.

WEISS, C. Produits verts: que choisir? Calypso Log v.165, p. 12-4, 1997
1. Em tempos de patrulhamento ecológico, é politicamente correto dizer tecnologia "limpa", em vez de "poupadora", termo que traduziria melhor o significado das novas tecnologias. 